Article

\title{
Energy Utilization Evaluation of Carbon Performance in Public Projects by FAHP and Cloud Model
}

\author{
Lin $\mathrm{Li}^{*}{ }^{\dagger}$, Fangfang Fan ${ }^{\dagger}, \mathrm{Li}$ Ma and Ziran Tang \\ School of Business, Hunan University, Changsha 410082, China; fanff@hnu.edu.cn (F.F.); \\ b12140013@hnu.edu.cn (L.M.); jordantang@hnu.edu.cn (Z.T.) \\ * Correspondence: li2518@hnu.edu.cn; Tel.: +86-731-8882-2899 \\ + These authors contributed equally to this work. \\ Academic Editors: Fausto Cavallaro and Marc A. Rosen \\ Received: 5 March 2016; Accepted: 29 June 2016; Published: 7 July 2016
}

\begin{abstract}
With the low-carbon economy advocated all over the world, how to use energy reasonably and efficiently in public projects has become a major issue. It has brought many open questions, including which method is more reasonable in evaluating the energy utilization of carbon performance in public projects when the evaluation information is fuzzy; whether an indicator system can be constructed; and which indicators have more impact on carbon performance. This article aims to solve these problems. We propose a new carbon performance evaluation system for energy utilization based on project processes (design, construction, and operation). Fuzzy Analytic Hierarchy Process (FAHP) is used to accumulate the indicator weights and cloud model is incorporated when the indicator value is fuzzy. Finally, we apply our indicator system to a case study of the Xiangiiang River project in China, which demonstrates the applicability and efficiency of our method.
\end{abstract}

Keywords: public projects; energy utilization evaluation; indicator system; FAHP model; cloud model

\section{Introduction}

Nature provides us the resources for economic development and takes back the wastes, e.g., the greenhouse gases. The scale of this exchange between nature and human society has been increasing, especially in the last few decades. Nevertheless, there are physical, biological and other limits set on the capacity of nature to produce the resources and absorb the wastes. Exceeding these limits will not only cause catastrophic, probably irreversible damages to the ecological balance in nature, but also prevent the economy from further development and make people's living conditions deteriorate. Currently, the prevailing haze weather in northern China demonstrates that such problems, also existing in many other countries and cultures, are becoming more and more serious and eventually force governments to take more measures to reduce greenhouse gas emissions. Let us consider the economic development of China as an example: in order to meet the needs of the new normal economy and promote economy growth steadily in China, the government strengthens large-scale investments on public projects. Over 400 infrastructure projects of seven categories were approved by the State Council of China with the total investment being more than $¥ 10$ trillion by the end of 2014 to 2016, and more than $¥ 7$ trillion has been invested in 2015 [1]. However, at the same time, public projects with large-scale investments also produce many negative effects on the environment and ecology. According to official statistics, the greenhouse gas emissions from China reached 665 tons in 2008; what is even worse, $83 \%$ of the total amount was carbon dioxide [2]. It has been pointed out that energy consumption per unit GDP of China was eight times Japan, four times United States, and twice as much as India and South Korea in 2010 [3]. The aforementioned data reflect that China pays a huge price for these economic achievements. If China continues to maintain this growth rate, environmental 
deterioration and energy shortages will be the biggest bottlenecks for economic development in the next 50 years.

To develop a low carbon economy, it is critical to reduce carbon emission effectively. The question is, who should bear the main responsibility. Cust [4] insists that the governments should play guiding roles in dealing with such issues. The construction of public projects has a significant impact on society, ecology and natural environment. It is necessary for the government to synthetically evaluate whether the construction of public projects meet the requirements of low-carbon economic development or not. The meaning of synthetic evaluation is that it is based on the whole process of public projects and evaluation indicators include three main parts, i.e., design, construction and operation indicators. Meanwhile, it also includes qualitative and quantitative indicators. Besides, randomness of linguistic decision-making information and the interaction of low carbon economy with low carbon energy utilization should be taken into account. Nevertheless, to our knowledge, this kind of research is still lacking at present. Thus, it is vital to study the evaluation of energy utilization in public projects under the low-carbon performance.

\subsection{The Performance Evaluation of Public Projects}

The evaluation of energy utilization belongs to the performance evaluation of public projects. The performance evaluation originally focuses on the financial evaluation, and then it develops into the evaluation of social benefits, which is primarily based on welfare economics and Keynesian theory (Keynesian economic theory is put forward by John Maynard Keynes, which mainly includes the effective demand, investment demand and consumption demand) [5]. In 1996, Green et al. [6] used data envelopment analysis (DEA) and cross-evaluation to rank projects. Up to now, the evaluation system has included evaluation indicators and models that comprehensively consider the economic, social, environmental and ecological factors. Earlier, a particular strand of literature used the improved earned value analysis (EVA), two-dimensional structure model and progressive evaluation model to evaluate project performance (Rodney [7]). Later, John et al. [8] proposed a performance evaluation system of cooperative construction projects in Hong Kong. Almost at the same time, Gabriel et al. [9] proposed the evaluation model combining incentives and certification targets together. Recently, Lee [10] used the integrated two-stage multi-criteria decision making (MCDM) approach to evaluate the relative weights of indicators and measure the relative efficiency of energy technologies against high oil prices. Furthermore, Seung et al. [11] adopted $6 \sigma$ principle to develop the method of improving the performance target and the method of measuring the performance improvement. However, none of these, DEA, improved EVA, etc., are systematic, and the interrelation between low-carbon energy utilization with public projects performance is not involved and the interaction of low carbon economy with low-carbon energy utilization has not been further studied. In addition, the above models neglect the influence of the public projects construction on low carbon economy and low carbon energy utilization.

\subsection{The Low-Carbon Economy Evaluation}

To date, the low-carbon economy evaluation models are widely studied. Before evaluating the low-carbon economy, it is necessary to establish a comprehensive indicator system. Therefore, some researchers focused on the indicator system, analyzed the main factors that influence the effect of the low-carbon economy [12,13], and considered the factors affecting carbon emissions and climate, which are population size, industrialization, urbanization and economic development [14]. In addition, Koji [15] designed a quantitative method to estimate low-carbon economy emissions from industry, commerce, transportation and residential areas separately. On the basis of an indicator system, many evaluation models are proposed from different aspects. For example, Zhang et al. [16] analyzed the regional low-carbon economy efficiency in China based on the super slacks-based measure (Super-SBM) model with $\mathrm{CO}_{2}$ emissions, the Super-SBM model considering undesirable outputs based on the SBM DEA framework. Nieto-Morote et al. [17] proposed an approach based on the Fuzzy Sets Theory and Analytic Hierarchy Process (AHP). Guo [18] used the AHP and the fuzzy factors to evaluate the 
low-carbon economy. However, these models do not integrate low-carbon economic data with the low carbon energy utilization. In addition, due to the complexities of the projects and the fuzziness of people's way of thinking, it is more appropriate for the decision-makers to describe their ideas in natural language. When natural language is involved, both randomness and fuzziness should be considered. In general, fuzziness mainly represents the uncertainty of the concept regarding the range of extension, and randomness is a form of contingency, the uncertainty of each event in a certain probability event set. Thus, we should take both of them into account in the evaluating process. Nevertheless, some researchers ignore the randomness of linguistic decision-making information $[19,20]$. Obviously, the chosen model should be more flexible and practical in dealing with fuzziness and randomness.

\subsection{Fuzzy Linguistic Variables and Cloud Model}

Generally, decision-makers tend to use fuzzy linguistic terms to express their viewpoints containing important information, which is difficult to quantify. Some progress has been made on this issue. Zadeh [21] proposed linguistic variable and applied it to approximate reasoning. Cabrerizo [22] studied the consistency of linguistic variables with incomplete information. Fan and Liu [23] proposed a method to deal with multi-granular linguistic information. Zhu et al. [24] evaluated projects using non-formatted text information based on multi-granular linguistic labels. In the past several decades, the problem of linguistic variables has been considered and many researchers studied evaluation models and proposed numerous methods, which can be classified into four types: (I) the linguistic computational model based on membership functions [25,26]; (II) the method based on symbols [27-29]; (III) the model based on the 2-tuple linguistic representation [30-32]; and (IV) the cloud model [33-35].

In recent years, the conversion from uncertain linguistic information to quantitative concept has become the focus of many researchers. Evaluation results will become more reasonable and the workload will be much less once this conversion problem is solved. Therefore, some researchers propose the cloud model, which considers fuzziness, randomness and their association relationship based on the normal distribution and the Gaussian membership function [33,36,37]. The main contribution of the cloud model is that it transforms qualitative concepts into quantitative ones with three parameters describing the numerical characters of qualitative concepts [34]. Therefore, the cloud model is more objective and less information-losing than other methods. It has been successfully applied to numerous fields, such as data mining [38], knowledge discovery [39], network security [40], image segmentation [41] and linguistic MCDM [42]. Certainly, there are other ways transforming uncertain linguistic information into numbers, such as the defuzzifying method [43], and transforming uncertain linguistic evaluation information into trapezoidal fuzzy numbers [44]. However, in the construction of indicator system, we found that it includes both quantitative and qualitative indicators. Moreover, there is no standard reference for experts to evaluate qualitative indicators. Uncertain linguistic information is given by the experts and increases the difficulty of evaluation. Fortunately, cloud model has outstanding performance in solving this problem. Therefore, cloud model is adopted in the present paper for the conversion between quantitative and qualitative concepts.

\subsection{Motivation}

Currently, there are some problems in the assessment of energy utilization in large public projects. For example, since natural language is flexible and reasonable, in order to truly express decision-makers' preferences, it is more appropriate for them to use the linguistic description instead of other descriptions to express their assessments $[45,46]$. However, the question is, which method is more reasonable to convert the linguistic variables to numbers. Moreover, when we evaluate energy utilization of carbon performance, problems like which indicator system can be used and which indicators of low carbon measures should be aimed at, are still pending and become barriers in the development of low carbon economy. Hence, it is urgent to study the performance evaluation of energy utilization within low-carbon economy. In this paper, we present a low-carbon evaluation indicator system, and a new 
evaluation model of carbon performance. As mentioned above, the cloud model and FAHP are more effective in describing qualitative concepts and providing new solutions to the evaluation problems. In this paper, we use the cloud model combined with FAHP to remove some deficiencies in the aforementioned research.

The rest of this paper is organized as follows. Section 2 introduces evaluation indicator system of energy utilization under carbon performance. The details of the evaluation model are given in Section 3. Section 4 presents an empirical example that shows that the methodology is practically applicable. Section 5 offers the conclusion.

\section{Indicator System}

In the evaluation of energy utilization of carbon performance in public projects, besides the environmental demand, many other factors should be taken into account. Through the analysis of the actual situation of public projects, we found that energy utilization of carbon performance evaluation indicator system should include the use of low-carbon technologies, low-carbon energy utilization, saving of resources, the use of renewable energy sources, as well as the impact of the project on the surrounding environment and emissions of other gases. Additionally, indicators are not just from construction stage of the project. Design and operation stages should also be taken into account. The quality of evaluation indicators directly affects the accuracy of the results. Thus, we should be aware of the low-carbon related factors in the process of the project. In this paper, the steps that we construct an indicator system are as follows.

First, we collect low-carbon energy evaluation indicators and public projects performance evaluation indicators by referring relevant literature [47-51], and transform some valuable information in the government announcements into indicators. We collect the relevant information on the Chinese Urban Low-carbon Economy Network and analyze the correlation of the information. Useful information is retained, such as "technology innovation is the key to the development of low-carbon economy", which means that technology of energy saving should be considered when we evaluate the energy utilization of carbon performance in public projects. After collecting indicators, we select the reasonable ones and optimize the structure of the indicator system by consulting with the experts and conduct membership analysis, and correlation and discriminability analysis based on the evaluation indicator construction principle. Through the above steps, 27 indicators have been retained. Public projects can be divided into three parts, i.e., design, construction and operation. Thus, we can divide the indicators into three major parts depending on the process of the project. Sometimes, the reliability and validity of the indicators may not meet our requirements, so we should verify the reliability and validity before constructing the indicator system. Based on all these considerations, we construct indicators to measure the energy utilization of carbon performance in public projects as follows.

From the aspect of the project process, the indicators can be divided into design, construction and operation indicator. Each indicator contains several specific indicators. Figure 1 illustrates an indicator system of energy utilization in public projects with 27 indicators: there are seven specific indicators under the design indicator, 13 specific indicators under the construction indicator, and seven specific indicators under the operation indicator. Table 1 gives details about what these specific indicators are, descriptions of the qualitative indicators and measurement of quantitative indicators.

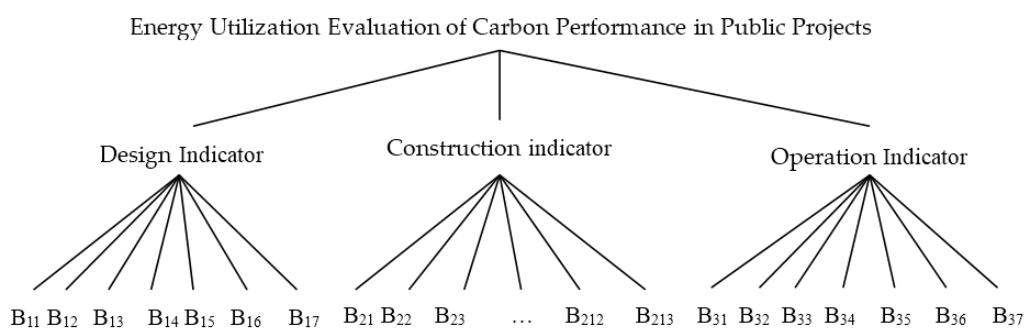

Figure 1. The evaluation indicator system of energy utilization in public projects. 
Table 1. The energy utilization evaluation indicators and indicator description.

\begin{tabular}{|c|c|}
\hline Indicator & Indicator Description \\
\hline $\begin{array}{l}\text { Reasonable arrangement degree of energy } \\
\text { recycling system } B_{11}\end{array}$ & $\begin{array}{l}\text { There is a scientific planning in the construction phase for the } \\
\text { project's energy recycling. }\end{array}$ \\
\hline $\begin{array}{l}\text { The utilization rate of renewable } \\
\text { energy } B_{12}\end{array}$ & $\begin{array}{l}\text { The utilization rate of renewable energy = The utilization of } \\
\text { renewable energy/The utilization of total energy }\end{array}$ \\
\hline The equipment efficiency $B_{13}$ & The effective availability of the equipment. \\
\hline $\begin{array}{l}\text { The utilization rate of resource } \\
\text { recycling } B_{14}\end{array}$ & $\begin{array}{l}\text { The rate of recyclable material = The amount of recyclable } \\
\text { materials / The total amount of all materials. }\end{array}$ \\
\hline $\begin{array}{l}\text { Energy saving construction method and } \\
\text { technology } B_{15}\end{array}$ & $\begin{array}{l}\text { Whether the energy saving construction method and technology } \\
\text { are used in the process of the projects construction or not. }\end{array}$ \\
\hline $\begin{array}{l}\text { The utilization degree of renewable energy } \\
\text { technology } B_{16}\end{array}$ & $\begin{array}{l}\text { The more we use the renewable energy technology in the } \\
\text { projects, the more carbon dioxide emissions we can reduce to } \\
\text { meet the requirements of low-carbon economy development. }\end{array}$ \\
\hline $\begin{array}{l}\text { The energy consumption in the } \\
\text { construction and transportation } \\
\text { process } B_{17}\end{array}$ & $\begin{array}{l}\text { In order to save the energy consumption, we adopt the } \\
\text { proximity principle for energy use in the construction process. }\end{array}$ \\
\hline $\begin{array}{l}\text { The amount of energy power saving in the } \\
\text { project(kilowatt) } B_{21}\end{array}$ & $\begin{array}{l}\text { The amount of power saving after the project completed. } \\
\text { Saving } 1 \text { kilowatt hour of power = reducing } 0.997 \mathrm{~kg} \text { carbon } \\
\text { dioxide emissions = reducing } 0.272 \mathrm{~kg} \text { "carbon" emissions }\end{array}$ \\
\hline $\begin{array}{l}\text { The amount of coal saving in the } \\
\text { project }(\mathrm{kg}) B_{22}\end{array}$ & $\begin{array}{l}\text { The amount of coal saving after the project completed. } \\
\text { Saving } 1 \mathrm{~kg} \text { of standard coal = reducing } 2.493 \mathrm{~kg} \text { carbon dioxide } \\
\text { emissions = reducing } 0.68 \mathrm{~kg} \text { "carbon" emissions }\end{array}$ \\
\hline $\begin{array}{l}\text { The amount of gasoline saving in the } \\
\text { project } B_{23}\end{array}$ & $\begin{array}{l}\text { Saving one liter of gasoline = reducing } 2.3 \mathrm{~kg} \text { carbon dioxide } \\
\text { emissions = reducing } 0.627 \mathrm{~kg} \text { "carbon" emissions }\end{array}$ \\
\hline $\begin{array}{l}\text { The amount of diesel saving in the } \\
\text { project } B_{24}\end{array}$ & $\begin{array}{l}\text { The amount of diesel saved after the project completed. } \\
\text { Saving one liter of diesel = reducing } 2.63 \mathrm{~kg} \text { carbon dioxide } \\
\text { emissions = reducing } 0.717 \mathrm{~kg} \text { "carbon" emissions }\end{array}$ \\
\hline The utilization rate of waste recycling $B_{25}$ & $\begin{array}{l}\text { The waste recycling in the project = The amount of waste } \\
\text { reduced by recycling the waste in the project/the total weight in } \\
\text { the construction and demolition of the project }\end{array}$ \\
\hline $\begin{array}{l}\text { The utilization of combustible gas } \\
\text { recycling } B_{26}\end{array}$ & $\begin{array}{l}\text { Combustible gas produced during the project should be } \\
\text { recycling, the situation of the repeated use. }\end{array}$ \\
\hline $\begin{array}{l}\text { The re-utilization degree of extra heat and } \\
\text { pressure } B_{27}\end{array}$ & $\begin{array}{l}\text { Re-use situation of the residual pressure and waste heat } \\
\text { in this project. }\end{array}$ \\
\hline $\begin{array}{l}\text { Highly-efficient utilization of water } \\
\text { resources } B_{28}\end{array}$ & $\begin{array}{l}\text { According to "making the best use of high quality water, and } \\
\text { saving low quality water" principle. }\end{array}$ \\
\hline $\begin{array}{l}\text { The utilization rate of recycling water } \\
\text { resources } B_{29}\end{array}$ & $\begin{array}{l}\text { In order to realize sewage recycling use, and improve the } \\
\text { recycling utilization of water resources, energy-saving } \\
\text { innovation technology for sewage disposing is used. }\end{array}$ \\
\hline $\begin{array}{l}\text { High-carbon emission energy } \\
\text { utilization } B_{210}\end{array}$ & $\begin{array}{l}\text { The utilization of energy with high-carbon emission } \\
\text { should be minimized. }\end{array}$ \\
\hline The carbon-dioxide emission reduced $B_{211}$ & The amount of carbon-dioxide emissions reduced. \\
\hline $\begin{array}{l}\text { The coefficient of energy carbon emission } \\
\text { in the project } B_{212}\end{array}$ & $\begin{array}{l}\text { The coefficient of energy carbon emission = carbon } \\
\text { emission/energy consumption, the index is used to check out } \\
\text { whether the structure of energy in the project meets the } \\
\text { requirements of low-carbon economy development. }\end{array}$ \\
\hline $\begin{array}{l}\text { The saving degree of resources utilization } \\
\text { in the process } B_{213}\end{array}$ & $\begin{array}{l}\text { The utilization degree of low carbon materials in the project, and } \\
\text { the level of using low-carbon technologies. }\end{array}$ \\
\hline Environment conservation $B_{31}$ & $\begin{array}{l}\text { The waste-disposing situation in the operation process, and the } \\
\text { complaints from the surrounding residents. }\end{array}$ \\
\hline
\end{tabular}


Table 1. Cont.

\begin{tabular}{ll}
\hline \multicolumn{1}{c}{ Indicator } & \multicolumn{1}{c}{ Indicator Description } \\
\hline The rate of planting in the project $B_{32}$ & $\begin{array}{l}\text { The rate of planting = planting area in the project/total area of } \\
\text { the project, the bigger the planting area are, the more the carbon } \\
\text { dioxide can be absorbed by the vegetation. }\end{array}$ \\
\hline Environmental noise $B_{33}$ & $\begin{array}{l}\text { To check out the level of the environment noise after the project } \\
\text { completed, the environmental noise should be minimized. }\end{array}$ \\
\hline Project impact in the natural landscape $B_{34}$ & $\begin{array}{l}\text { To check out whether the project influences the local natural } \\
\text { landscape, and whether the influence is positive or negative. }\end{array}$ \\
\hline $\begin{array}{l}\text { Emissions of sewage pollution in the } \\
\text { project } B_{35}\end{array}$ & $\begin{array}{l}\text { After the standard disposal, sewage emissions in the } \\
\text { implementation should be minimized. }\end{array}$ \\
\hline $\begin{array}{l}\text { Emissions of waste pollution in the } \\
\text { project } B_{36}\end{array}$ & $\begin{array}{l}\text { After the standard disposal, waste emissions in the } \\
\text { implementation should be minimized. }\end{array}$ \\
\hline Emissions of exhaust gas in the project $B_{37}$ & $\begin{array}{l}\text { After the standard disposal, exhaust gas emissions } \\
\text { should be minimized. }\end{array}$ \\
\hline
\end{tabular}

\section{Methodology}

In this section, we propose an evaluation model, including the method for obtaining indicator weights and the cloud model. By comparing various methods, we adopt fuzzy analytic hierarchy process (FAHP) to obtain the indicator weights, and then use the cloud model for the evaluation.

\subsection{FAHP Approach}

In most literature, AHP is used to determine the weight of the indicators. The key of AHP is to establish the judgment matrix, which directly affects the scientificity and rationality of the result. However, according to the research result in AHP, judgment matrix of AHP can better reflect the extreme importance of the indicators. Unfortunately, the degrees of importance between indicators are almost "much more", "more" and "slightly more" in the indicator system we put forward; thus, is not appropriate to continue using AHP to get the weight of indicators. Therefore, we introduce fuzzy analytic hierarchy process (FAHP). Compared with AHP, FAHP uses a different method to obtain the relative importance of each indicator weight, and it can perfectly reflect the degree of importance, which were previously classified into "much more", "more" and "slightly more" [52]. Moreover, FAHP can also effectively alleviate the problem of ambiguity [53]. Thus, FAHP is more suitable to assign weights than AHP in public projects.

\subsubsection{Getting the Fuzzy Consistent Judgment Matrix}

As mentioned above, $B_{i}$ represents the evaluation indicator, $i=1,2, \cdots, n$ and $n$ is the number of indicators. Let $r_{i j}$ describe the importance degree (i.e., fuzzy relation's membership degree) between $B_{i}$ and $B_{j}$, where $i=1,2, \ldots, n, j=1,2, \ldots, n$. According to the literature (Calabrese et al. [54]), the 0.1-0.9 scale is adopted, and the relationships are found in Table 2.

Table 2. Importance degree and corresponding value.

\begin{tabular}{ccc}
\hline Scale & Definition & Illustration \\
\hline$r_{i j}=0.9$ & Absolutely more important & $B_{i}$ is absolutely more important than $B_{j}$ \\
$r_{i j}=0.8$ & Much more important & $B_{i}$ is much more important than $B_{j}$ \\
$r_{i j}=0.7$ & More important & $B_{i}$ is more important than $B_{j}$ \\
$r_{i j}=0.6$ & Slightly more important & $B_{i}$ is slightly more important than $B_{j}$ \\
$r_{i j}=0.5$ & Equally important & $B_{i}$ is as important as $B_{j}$ \\
& Reverse comparison & $r_{j i}=1-r_{i j}$ \\
\hline
\end{tabular}


By comparing various criteria or indicators, the scholars in related field give $r_{i j}$; thus, we get the fuzzy judgment matrix.

$$
R=\left[\begin{array}{cccc}
r_{11} & r_{12} & \ldots & r_{1 n} \\
r_{21} & r_{12} & \ldots & r_{2 n} \\
\ldots & \ldots & \ldots & \ldots \\
r_{n 1} & r_{n 2} & \ldots & r_{n n}
\end{array}\right]
$$

\subsubsection{The Indicator Weights}

Based on the method from the literature, we can obtain indicator weights [55,56]. $w_{i}$ is the weight of $B_{i}$. The number of experts is $m$, and these $m$ experts give $m$ different fuzzy consistent judgment matrices; for instance, expert $k$ gives the fuzzy consistent judgment matrix $R^{(k)}, k=1,2, \cdots, m$.

$$
R^{(k)}=\left[\begin{array}{cccc}
r_{11}{ }^{(k)} & r_{12}{ }^{(k)} & \ldots & r_{1 n}(k) \\
r_{21}(k) & r_{12}{ }^{(k)} & \ldots & r_{2 n}(k) \\
\ldots & \ldots & \ldots & \ldots \\
r_{n 1}{ }^{(k)} & r_{n 2}(k) & \ldots & r_{n n}(k)
\end{array}\right]
$$

A new matrix can be obtained by averaging these matrices, i.e., $\bar{R}=\frac{\sum_{k=1}^{m} R^{(k)}}{m}$.

$$
\bar{R}=\left[\begin{array}{cccc}
\overline{r_{11}} & \overline{r_{12}} & \ldots & \overline{r_{1 n}} \\
\overline{r_{21}} & \overline{r_{22}} & \ldots & \overline{r_{2 n}} \\
\ldots & \ldots & \ldots & \ldots \\
\overline{r_{n 1}} & \overline{r_{n 2}} & \ldots & \overline{r_{n n}}
\end{array}\right]
$$

When the fuzzy judgment matrix is consistent, the above matrix has the following properties:

(1) $\overline{r_{i i}}=0.5,(i, j=1,2, \cdots, n)$

(2) $\overline{r_{i j}}=1-\overline{r_{j i}},(i, j=1,2, \cdots, n)$

(3) $\overline{r_{i j}}=\overline{r_{i k}}-\overline{r_{j k}},(i, j=1,2, \cdots, n)$

When the matrix is consistent, the weight is obtained by Equation (4).

$$
w_{i}=\frac{1}{n}-\frac{1}{2 \beta}+\frac{1}{n} \sum_{k=1}^{m} \bar{r}_{i k} i=1,2, \cdots, n ; \beta \geqslant(n-1) / 2
$$

When the matrix is not consistent, the equation of weight is,

$$
w_{i}=\frac{1}{n}-\frac{n}{4 \beta(n-1)}+\frac{1}{2 \beta(n-1)} \sum_{k=1}^{n} \bar{r}_{i k} i=1,2, \cdots, n ; \beta \geqslant(n-1) / 2
$$

where $\beta$ is a measure of the difference degree between the judgment elements, and is generally affected by the number of objects and the extent of the size. We take $\beta=(n-1) / 2$ as an example; the difference caused by $\beta$ is small when $n$ is large enough. Therefore, we can calculate the weights $w_{i}$ of the indicators $B_{i}$.

\subsection{Cloud Model}

\subsubsection{The Concept of Cloud}

The Cloud model is used to transform qualitative linguistic information into corresponding membership degree, and the model also combines the fuzziness and randomness of the natural linguistic [57]. 
Let $U$ be the universe of discourse and $T$ be a qualitative concept in $U$. If $x(x \subseteq X)$ is a random realization of the concept $T, x$ satisfies $x: N\left(E_{x}, E_{n}^{\prime 2}\right)$ and $E_{n}: N\left(E_{n}^{\prime}, H_{e}^{2}\right), \mu \in[0,1]$ is the certainty degree of $x$ belonging to T. $\mu$ is the membership grade,

$$
\mu=\exp \left[-\frac{\left(x-E_{x}\right)^{2}}{2\left(E_{n}^{\prime}\right)^{2}}\right]
$$

Then, the distribution of $x$ in the universe $U$ is called a normal cloud (referred to as "cloud" in the rest of this paper), and the cloud can be denoted as $(x, \mu)$. For simplicity of notation, it is shown as follows,

$$
\mu_{T}(X): U \rightarrow[0,1], \forall x \in X,(X \subseteq U), x \rightarrow \mu_{T}(x)
$$

Based on the cloud theory, the mapping relationship between element $x$ and relevant concept $T$ membership degree is different with the traditional fuzzy membership degree.

The normal distribution is the basis of cloud model. Since the expectation curve of the cloud is close to normal or half-normal distribution in social and natural sciences, the normal distribution becomes universal. According to the numerical characteristics of cloud, we can understand the concept of qualitative and quantitative characteristics. The three parameters, the expectation $E_{x}$, the entropy $E_{n}$ and the ultra-entropy $H_{e}$, are the digital characteristics of the cloud. The expectation $E_{x}$ is the expected value of domain space in the qualitative linguistic concept, and $E_{x}$ is the best representative value of qualitative linguistic concept. The entropy $E_{n}$ is the acceptable range value of domain space in the qualitative concept and measures fuzziness of qualitative concept. In addition, $E_{n}$ reflects the probability of linguistic value and the randomness of cloud droplets appear in the qualitative concept. Furthermore, the entropy represents the relevance of fuzziness and randomness. The ultra-entropy $H_{e}$ is the entropy of entropy $E_{n}$, which is the grade of membership of random variation, and indicates the discrete degree and thickness of cloud droplet. The cloud model fully expresses the fuzziness and randomness of the qualitative linguistic, thus is more objective than the other methods.

\subsubsection{The Level of Evaluation and Numerical Property}

It can be seen from the introduction that numerous studies do not deal with uncertain linguistic, especially when the qualitative linguistic variables are interval values. The cloud model is an effective way to solve this problem. The key idea of the cloud model is to transform vague linguistic variables into clouds and build the clouds. According to the three parameters of the last cloud, result of the assessment is clear.

To describe the method explicitly, let us start with some explanations.

- Fuzzy linguistic variable

If $S=\left\{s_{\partial} / \partial=-t, \ldots, t, t \in N\right\}$ is a finite and totally ordered discrete term set, $\mathrm{N}$ is the set of all non-negative integers, and $s_{\partial}$ represents the possible value of a linguistic variable. Let $R_{m}$ be $\left(a_{i j}^{m}\right)_{s \times n}$ where $R_{m}$ is the uncertain linguistic variable matrix given by the expert $E_{m} ; a_{i j}$ denotes the interval linguistic values, where $a_{i j}=\left[s_{i}, s_{j}\right],\left(s_{i}, s_{j}\right) \in S,-t \leqslant i \leqslant j \leqslant t$; and $s_{-t}$ and $s_{t}$ represent the lower limit and upper limit of linguistic variables [58], respectively. The values of linguistic variables are not numbers. The evaluation standard of the present study adopts five Likert scales $S$, defined as

$$
S=\left\{s_{-2}=\text { poor }, s_{-1}=\text { fair }, s_{0}=\text { average, } s_{1}=\text { good, } s_{2}=\text { excellent }\right\}
$$

For instance, if $a_{i j}=\left[s_{1}, s_{2}\right]$, it means that the expert's assessment for indicator is between "good" and "excellent", and if $a_{i j}=\left[s_{1}, s_{1}\right]$, it means that the expert's evaluation tends to be "good". 
- Transforming linguistic variables into clouds

Since we cannot manually interpret linguistic variable, transforming the non-numeric linguistic variable into the digital one is vital. According to the method proposed by [59] in 2005, assuming that the linguistic of index assessment scale for experts is $n,\left[X_{\min }, X_{\max }\right]$ is the effective domain set by scholars and $n$ is used to represent the linguistic value. If a cloud in the middle is denoted by $Y_{0}\left(E_{x_{0}}, E_{n_{0}}, H_{e_{0}}\right)$ in the Likert scale and is an odd number, then the adjacent cloud of the middle cloud can be defined as, respectively,

$$
\begin{aligned}
Y_{-1}\left(E_{x_{-1}}, E_{n_{-1}}, H_{e_{-1}}\right), & Y_{1}\left(E_{x_{1}}, E_{n_{1}}, H_{e_{1}}\right), \ldots, Y_{(1-n) / 2}\left(E_{x_{(1-n) / 2}}, E_{n_{(1-n) / 2}}, H_{e_{(1-n) / 2}}\right), \\
& Y_{(n-1) / 2}\left(E_{x_{(n-1) / 2}}, E_{n_{(n-1) / 2}}, H_{e_{(n-1) / 2}}\right)
\end{aligned}
$$

The method of generating five clouds is based on the golden section method. The numerical feature of cloud is as follows:

$$
\begin{gathered}
E_{x_{0}}=\left(X_{\min }+X_{\max }\right) / 2, E_{x_{-2}}=X_{\min }, E_{x_{2}}=X_{\max }, E_{x_{-1}}=E_{x_{0}}-0.382\left(X_{\min }+X_{\max }\right) / 2, \\
E_{x_{1}}=E_{x_{0}}+0.382\left(X_{\min }+X_{\max }\right) / 2 ; E_{n_{0}}=0.618 E_{n_{+1}}, E_{n_{-1}}=E_{n_{+1}}=0.382\left(X_{\min }-X_{\max }\right) / 6, \\
E_{n_{-2}}=E_{n_{+2}}=E_{n_{+1}} / 0.618 .
\end{gathered}
$$

For a given $H_{e_{0}}, H_{e_{-1}}=H_{e_{1}}=H_{e_{0}} / 0.618$ [59].

If the number of clouds is more than five, one may adopt the method developed in [60]. For the studies in the present paper, we restrict ourselves to the cases of $n=5$. Based on the definitions above, the process of the cloud model can be specified in the following steps, as illustrated in Figure 2.

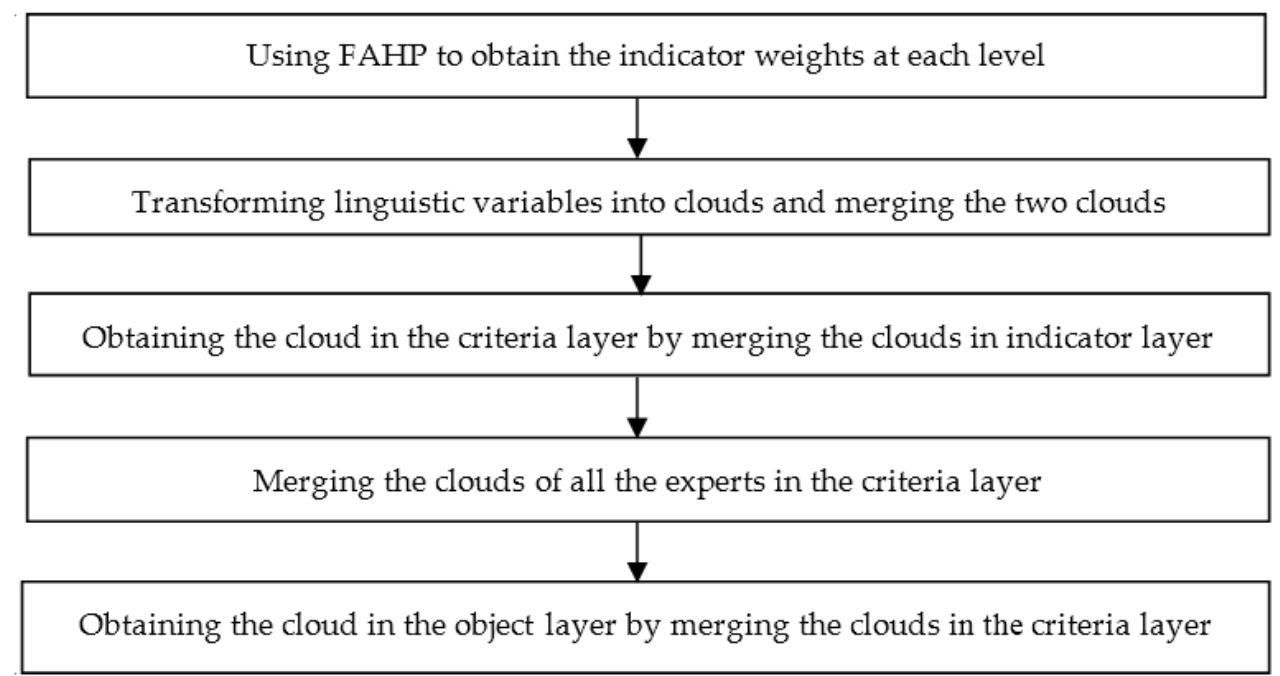

Figure 2. Evaluation steps.

Step 1: If there are $b$ evaluation indicators in the indicator layer, $c$ evaluation indicators in the criterion layer, we use FAHP to obtain the corresponding indicator weight of each level, and the weights $w_{b}, w_{c}$ satisfies $w_{b} \in[0,1], w_{c} \in[0,1], w_{1}+w_{2}+\ldots+w_{b}=1, w_{1}+w_{2}+\ldots+w_{c}=1$.

Step 2: If $\left[s_{i}, s_{j}\right]$ are the uncertain linguistic variables given by experts, they should be translated into two clouds. Let $s_{i} \rightarrow y_{i}=\left(E_{x i}, E_{n i}, H_{e i}\right)$ be the left cloud and $s_{j} \rightarrow y_{j}=\left(E_{x j}, E_{n j}, H_{e j}\right)$ be the right cloud. Comprehensive cloud $\hat{y}=\left(E_{x}, E_{n}, H_{e}\right)$ can be obtained by merging the two clouds. However, there are generally two cases, one is the two clouds disjoint, another is them intersect. Therefore, we need to calculate it separately. 
When the left cloud and right cloud disjoint, the calculation method is illustrated in Equation (7).

$$
\begin{gathered}
E_{x_{q}}=\left[\left(E_{x_{i}}+3 E_{n_{i}}\right)+\left(E_{x_{j}}-3 E_{n_{j}}\right)\right] / 2 \\
E_{n_{q}}=\max \left\{\left(E_{x}-E_{x_{i}}\right) / 3,\left(E_{x_{j}}-E_{x}\right) / 3\right\} \\
H_{e_{q}}=\sqrt{H_{e_{i}}^{2}+H_{e_{j}}^{2}}
\end{gathered}
$$

When the left cloud and right cloud intersect, the calculation method is illustrated in Equation (8).

$$
\begin{gathered}
E_{x_{q}}=\frac{E_{x_{i}} E_{n_{i}}+E_{x_{j}} E_{n_{j}}}{E_{n_{i}}+E_{n_{j}}} \\
E_{n_{q}}=\max \left(E_{n_{i}}+\left(E_{x}-E_{x_{i}}\right) / 3, E_{n_{j}}+\left(E_{x_{j}}-E_{x}\right) / 3\right) \\
H_{e_{q}}=\sqrt{H_{e_{i}}^{2}+H_{e_{j}}^{2}}
\end{gathered}
$$

where $q=1,2, \cdots, b, b$ is the number of evaluation indicators in the indicator layer.

In this process, we obtain the comprehensive clouds of the indicator layer, and make preparation for the cloud merging in the criterion layer.

Step 3: From the steps above we know that there are $b$ fundamental clouds according to every expert's linguistic assessment, i.e., $Y_{1}^{m}\left(E_{x_{1}}, E_{n_{1}}, H_{e_{1}}\right), Y_{2}^{m}\left(E_{x_{2}}, E_{n_{2}}, H_{e_{2}}\right), \ldots, Y_{b}^{m}\left(E_{x_{b}}, E_{n_{b}}, H_{e_{b}}\right)$, where $m$ is the number of respondents. Based on the fundamental clouds, a floating cloud can be generated. If the digital characteristics of generated floating clouds is $Y^{m}\left(E_{x_{p}}^{m}, E_{n_{p}}^{m}, H_{e_{p}}^{m}\right)$, then

$$
\begin{gathered}
E_{x_{p}}^{m}=w_{1} E_{x_{1}}+w_{2} E_{x_{2}}+\cdots+w_{b} E_{x_{b}} \\
E_{n_{p}}^{m}=\frac{w_{1} E_{x_{1}} E_{n_{1}}+w_{2} E_{x_{2}} E_{n_{2}}+\cdots+w_{b} E_{x_{b}} E_{n_{b}}}{w_{1} E_{x_{1}}+w_{2} E_{x_{2}}+\cdots+w_{b} E_{x_{b}}} \\
H_{e_{p}}^{m}=\sqrt{H_{e_{1}}^{2}+H_{e_{2}}^{2}+\cdots H_{e_{b}}^{2}}
\end{gathered}
$$

In the above Equation, $p=1,2, \cdots, c, w_{i}, i=1,2, \cdots, b$ denotes the corresponding indicator weight.

In this step, we obtain clouds that correspond with the indicators in the criterion layer by merging the cloud droplets in the index layer.

Step 4: Assume that there are $m$ respondents, the weight of each respondent is $\partial_{m}$, satisfying $\partial_{m} \in[0,1], \partial_{1}+\partial_{2}+\ldots+\partial_{h}=1$, where $m=1,2, \ldots h$. Most of the respondents are public projects practitioners and academicians, and the weight represents the evaluation of respondents about their work experiences, authorities and research results. Specific weights can be obtained by scoring each other, then unitizing the scores. Combing the weights and the evaluation, we obtain a comprehensive final assessment of all respondents, i.e., $\bar{Y}\left(\bar{E}_{x_{p}}, \bar{E}_{n_{p}}, \bar{H}_{e_{p}}\right)$.

$$
\begin{gathered}
\bar{E}_{x_{p}}=\sum_{m=1}^{h} \partial_{m} E_{x_{p}}^{m} \\
\bar{E}_{n_{p}}=\frac{\sum_{m=1}^{h} \partial_{m} E_{x_{p}}^{m} E_{n_{p}}^{m}}{\sum_{m=1}^{h} \partial_{m} E_{x_{p}}^{m}} \\
\bar{H}_{e_{p}}=\sqrt{\sum_{m=1}^{h} H_{e_{p}}^{m 2}}
\end{gathered}
$$

where $p=1,2, \cdots, c, m=1,2, \cdots, h$. 
Based on the two steps above, we can obtain the comprehensive clouds of the indicators in the criteria layer, namely, the evaluation value of each indicator in the criteria layer.

Step 5: After finding $c$ comprehensive clouds in the criteria layer, we can obtain the final cloud drop $Y\left(E_{x}, E_{n}, H_{e}\right)$ using the method similar to Step 4 . The final cloud is the comprehensive evaluation value of the public project,

$$
\begin{gathered}
E_{x}=w_{1} \bar{E}_{x_{1}}+w_{2} \bar{E}_{x_{2}}+\cdots+w_{c} \bar{E}_{x_{c}} \\
E_{n}=\frac{w_{1} \bar{E}_{x_{1}} \bar{E}_{n_{1}}+w_{2} \bar{E}_{x_{2}} \bar{E}_{n_{2}}+\cdots+w_{c} \bar{E}_{x_{c}} \bar{E}_{n_{c}}}{w_{1} \bar{E}_{x_{1}}+w_{2} \bar{E}_{x_{2}}+\cdots+w_{c} \bar{E}_{x_{c}}} \\
H_{e}=\sqrt{\bar{H}_{e_{1}}^{2}+\bar{H}_{e_{2}}^{2}+\cdots+\bar{H}_{e_{c}}^{2}}
\end{gathered}
$$

Through the steps of calculating indicator weights, transforming linguistic variables into clouds and merging the clouds, the cloud for each indicator is obtained. Since the cloud model incorporates the fuzziness and randomness of a qualitative concept with three numerical characteristics, it is very clear to see the evaluation score as well as the effects of fuzziness and randomness.

\section{Empirical Results}

In this section, we take the River Control Project of the Xiangjiang River as an example, and use the method proposed in Section 3 to evaluate the energy utilization of carbon performance in public projects. The feasibility of our method can be demonstrated by this example and it can also work as a reference for similar evaluation problems.

\subsection{Project Introduction}

In recent years, the Xiangjiang River of Hunan Province, China has significantly changed in drought seasons. The low water level of the Xiangjiang River decreased substantially. According to the government data, the lowest water level before 2008 was $25.15 \mathrm{~m}$ in 2007, while it became only $20.24 \mathrm{~m}$ in 2015, and the drought season in Hunan province usually lasts up to six months. This low-water-level problem not only threatens the urban water supply as the consumption of city water keeps increasing, but also affects the grade of waterway and the shipping capacity. To fix these problems, the local government in Changsha, Hunan initiated the River Control Projects. The main constructions of these projects include navigation lock, spillway, hydropower station, dam bypass, entrance roads, administrative zone and accessory constructions.

\subsection{Weight Results}

Before evaluating by the cloud model, we should obtain the weights of indicators in each level. FAHP can perfectly reflect the degree of importance and effectively reduce ambiguity; therefore, when it comes to fuzzy linguistic information evaluation, it is the better way to obtain the weights. Combined with cloud model, it can significantly reduce the fuzziness and improve the accuracy of evaluation.

We will put individual sub-projects of the city-river dam project together, and evaluate them as a group. As mentioned in the previous section, there are three layers of the indicators and there are three indicators in the criteria layer: the design indicator $B_{1}$, the construction indicator $B_{2}$ and the operational indicator $B_{3}$. We take the criteria layer as example to illustrate how to determine the weight of each indicator by FAHP. In addition, we send the questionnaire to six experts in the field of public projects. According to opinions of experts, there are six comparison judgment matrices, $R_{1}, R_{2}$, $R_{3}, R_{4}, R_{5}$ and $R_{6}$, in accordance with three indicators in the criteria layer.

$$
R_{1}=\left(\begin{array}{ccc}
0.5 & 0.5 & 0.6 \\
0.5 & 0.5 & 0.6 \\
0.4 & 0.4 & 0.5
\end{array}\right) R_{2}=\left(\begin{array}{lll}
0.5 & 0.4 & 0.5 \\
0.6 & 0.5 & 0.5 \\
0.5 & 0.5 & 0.5
\end{array}\right) R_{3}=\left(\begin{array}{lll}
0.5 & 0.3 & 0.6 \\
0.7 & 0.5 & 0.4 \\
0.4 & 0.6 & 0.5
\end{array}\right)
$$




$$
R_{4}=\left(\begin{array}{lll}
0.5 & 0.4 & 0.5 \\
0.6 & 0.5 & 0.6 \\
0.5 & 0.4 & 0.5
\end{array}\right) R_{5}=\left(\begin{array}{lll}
0.5 & 0.6 & 0.7 \\
0.4 & 0.5 & 0.7 \\
0.3 & 0.3 & 0.5
\end{array}\right) R_{6}=\left(\begin{array}{ccc}
0.5 & 0.6 & 0.6 \\
0.4 & 0.5 & 0.6 \\
0.4 & 0.4 & 0.5
\end{array}\right)
$$

Calculating the average of six comparison judgment matrices above, we obtain

$$
\bar{R}=\left(\begin{array}{ccc}
0.5 & 0.47 & 0.58 \\
0.53 & 0.5 & 0.57 \\
0.42 & 0.43 & 0.5
\end{array}\right)
$$

Since the matrix $\bar{R}$ is consistent, we use Equation (4) to calculate the corresponding weight of the indicators. Let $\beta=(n-1) / 2, n=3$, and $w_{1}, w_{2}$, and $w_{3}$ denote the weights of $B_{1}, B_{2}$, and $B_{3}$, respectively.

Therefore, we can calculate weights of three indicators, i.e., $w_{1}=0.42, w_{2}=0.33$, and $w_{3}=0.25$ in the criteria layer. Similarly, using the FAHP, we can calculate the weight of the indicators and the comprehensive weight of indicator, (Table 3).

Table 3. The weight table.

\begin{tabular}{ccc}
\hline Criteria Layer Weight & Indicator Weight & Comprehensive Weight \\
\hline & $B_{11}(0.12)$ & 0.0504 \\
$B_{12}(0.16)$ & 0.0672 \\
$B_{13}(0.07)$ & 0.0294 \\
$B_{1}(0.42)$ & $B_{14}(0.24)$ & 0.1008 \\
& $B_{15}(0.09)$ & 0.0378 \\
& $B_{16}(0.13)$ & 0.0546 \\
& $B_{17}(0.19)$ & 0.0798 \\
\hline$B_{21}(0.14)$ & 0.0462 \\
$B_{22}(0.05)$ & 0.0165 \\
$B_{23}(0.07)$ & 0.0231 \\
$B_{24}(0.05)$ & 0.0165 \\
$B_{25}(0.05)$ & 0.0165 \\
$B_{26}(0.11)$ & 0.0363 \\
$B_{27}(0.06)$ & 0.0198 \\
$B_{2}(0.33)$ & $B_{28}(0.09)$ & 0.0198 \\
& $B_{29}(0.06)$ & 0.0198 \\
& $B_{210}(0.09)$ & 0.0297 \\
& $B_{211}(0.08)$ & 0.0264 \\
& $B_{212}(0.07)$ & 0.0231 \\
$B_{213}(0.11)$ & 0.0363 \\
\hline$B_{3}(0.25)$ & $B_{31}(0.16)$ & 0.0400 \\
& $B_{32}(0.13)$ & 0.0325 \\
& $B_{33}(0.12)$ & 0.0300 \\
$B_{34}(0.08)$ & 0.0200 \\
& $B_{35}(0.19)$ & 0.0475 \\
$B_{36}(0.10)$ & 0.0250 \\
$B_{37}(0.22)$ & 0.0550 \\
\hline
\end{tabular}

Note: According to the Equations (1)-(5), weights of the indicators are obtained.

\subsection{Evaluation Results}

After getting the weight of indicators, we use the questionnaire form for survey. Thirty-seven experts of the city river multi-purpose project completed the survey. In the end, we received 34 valid questionnaires and retrieved the original data of multi-purpose projects performance evaluation. We then input these data into the cloud model to estimate the performance of the project energy utilization. 
The questionnaire uses the interval method, in which the experts will give an assessment interval, such as $\left[s_{-1}, s_{0}\right],\left[s_{1}, s_{1}\right]$ based on what they know about the subject. Besides, the evaluate grade has five classes, i.e., excellent (90-100 points), good (80-90 points), average (60-80 points), fair (40-60 points) and poor ( $0-40$ points). The calculation steps are as follows:

First, we determine the value of each cloud based on the Likert scale and use the golden section method to generate five clouds, and the conclusion domain, i.e., $\left[X_{\min }, X_{\max }\right]=[0,100]$, where $H_{e_{0}}=0.1$, and then we find the numerical characteristics of the five clouds as,

$$
\begin{aligned}
& E_{x_{0}}=\left(X_{\min }+X_{\max }\right) / 2=50, E_{x_{-2}}=X_{\min }=0, E_{x_{2}}=X_{\max }=100, \\
& E_{x_{-1}}=E_{x_{0}}-0.382\left(X_{\min }+X_{\max }\right) / 2=30.9, E_{x_{1}}=E_{x_{0}}+0.382\left(X_{\min }+X_{\max }\right) / 2=69.1, \\
& E_{n_{-1}}=E_{n_{+1}}=0.382\left(X_{\min }-X_{\max }\right) / 6=6.37, E_{n_{0}}=0.618 E_{n_{+1}}=3.93, E_{n_{-2}}=E_{n_{+2}}=E_{n_{+}} / 0.618=10.31, \\
& H_{e_{-1}}=H_{e_{1}}=H_{e_{0}} / 0.618=0.16, H_{e_{-2}}=H_{e_{2}}=H_{e_{+1}} / 0.618=0.26 .
\end{aligned}
$$

Thus, these five clouds are $Y_{-2}(0,10.31,0.26), \quad Y_{-1}(30.9,6.37,0.16), \quad Y_{0}(50,3.93,0.1)$, $Y_{+1}(69.1,6.37,0.16)$ and $Y_{+2}(100,10.31,0.26)$, respectively. Figure 3 illustrates the five clouds of the cloud model.

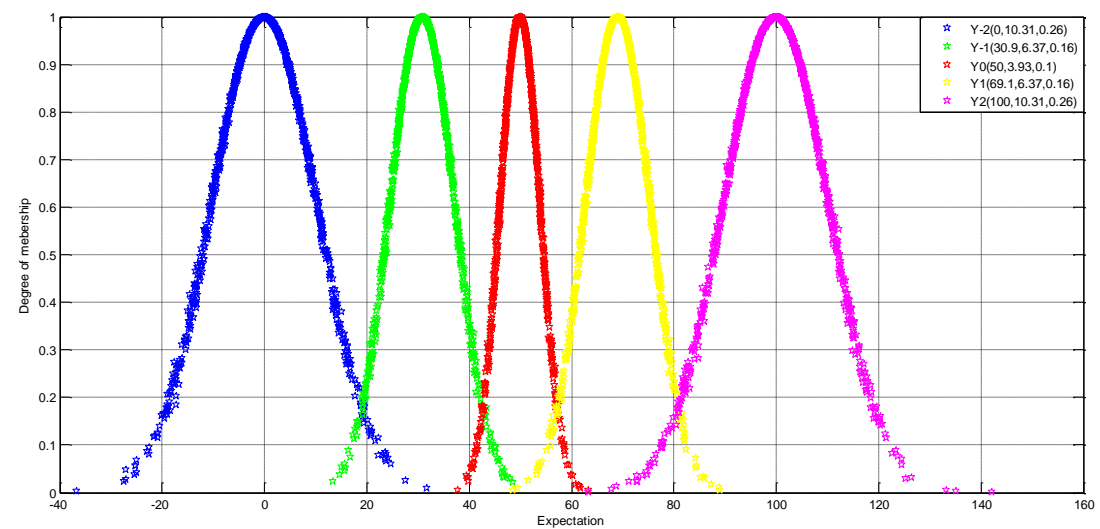

Figure 3. The evaluation result clouds.

Second, the floating clouds are merged. For example, indicators evaluation results of Expert 1 are shown in the Table 4. The information is fuzzy, and we need to build the two clouds. If the two clouds are disjoint, e.g., $B_{12}$, we use Equation (7) to obtain the comprehensive cloud, i.e., $Y_{B_{12}}(78.64,7.12,0.31)$. If the two clouds are joint, e.g., $B_{11}$, we use Equation (8) to obtain the comprehensive cloud, i.e., $Y_{B_{11}}(100,10.31,0.37)$. Similarly, the other comprehensive clouds of the indicators under $B_{1}$ can be obtained. The results are shown in Table 4 .

We then calculate the evaluation of the Expert 1 about $B_{1}$ based on Equation (9), i.e., $Y_{B_{1}}(70.91,6.88,0.71), Y_{B_{2}}(67.22,7.97,0.79)$, and $Y_{B_{3}}(61.82,5.87,0.50)$. Similarly, we can calculate the evaluation of other experts about $B_{1}, B_{2}$, and $B 3$. According to the scores given by respondents, the their weights can be obtained, i.e., $(0.031,0.028,0.025,0.03,0.031,0.025,0.03,0.035,0.028,0.033,0.027$, $0.03,0.026,0.031,0.026,0.032,0.025,0.034,0.028,0.03,0.027,0.03,0.027,0.028,0.029,0.034,0.03,0.028$, $0.03,0.025,0.032,0.029,0.035,0.031)$.

According to Equation (10), the comprehensive cloud is the final result, $\bar{Y}_{B_{1}}(71.88,6.97,0.69)$. Similarly, we can calculate $\bar{Y}_{B_{2}}(66.89,7.57,0.77)$ and $\bar{Y}_{B_{3}}(63.58,6.41,0.81)$.

Finally, according to Equation (11), the comprehensive evaluation of low carbon economy of public works project is calculated, i.e., $Y(68.16,967,1.31)$. We then can draw the cloud picture. Figure 4 illustrates the three parameters of the result. 
Table 4. The comprehensive cloud of the indicators under $B_{1}$

\begin{tabular}{cccc}
\hline Indicators & $\begin{array}{c}\text { The Assessment Results of } \\
\text { Expert 1 }\end{array}$ & $\begin{array}{c}\text { Comprehensive Cloud } \\
\left(E_{x}, E_{n}, H_{e}\right)\end{array}$ & Indicator Weights $w_{i j}$ \\
\hline$B_{11}$ & {$\left[s_{2}, s_{2}\right]$} & $(100,10.31,0.37)$ & 0.12 \\
$B_{12}$ & {$\left[s_{1}, s_{2}\right]$} & $(78.64,7.12,0.31)$ & 0.16 \\
$B_{13}$ & {$\left[s_{-1}, s_{0}\right]$} & $(44.11,4.67,0.19)$ & 0.07 \\
$B_{14}$ & {$\left[s_{1}, s_{1}\right]$} & $(69.10,6.37,0.23)$ & 0.24 \\
$B_{15}$ & {$\left[s_{1}, s_{2}\right]$} & $(78.64,7.12,0.31)$ & 0.09 \\
$B_{16}$ & {$\left[s_{1}, s_{1}\right]$} & $(69.10,6.37,0.23)$ & 0.13 \\
$B_{17}$ & {$\left[s_{0}, s_{1}\right]$} & $(55.89,4.40,0.19)$ & 0.19 \\
$B_{21}$ & {$\left[s_{1}, s_{1}\right]$} & $(69.10,6.37,0.23)$ & 0.14 \\
$B_{22}$ & {$\left[s_{0}, s_{1}\right]$} & $(55.89,4.40,0.19)$ & 0.05 \\
$B_{23}$ & {$\left[s_{0}, s_{1}\right]$} & $(55.89,4.40,0.19)$ & 0.07 \\
$B_{24}$ & {$\left[s_{-1}, s_{0}\right]$} & $(44.11,4.67,0.19)$ & 0.05 \\
$B_{25}$ & {$\left[s_{1}, s_{1}\right]$} & $(69.10,6.37,0.23)$ & 0.05 \\
$B_{26}$ & {$\left[s_{1}, s_{1}\right]$} & $(69.10,6.37,0.23)$ & 0.11 \\
$B_{27}$ & {$\left[s_{0}, s_{1}\right]$} & $(55.89,4.40,0.19)$ & 0.06 \\
$B_{28}$ & {$\left[s_{1}, s_{2}\right]$} & $(78.64,7.12,0.31)$ & 0.09 \\
$B_{29}$ & {$\left[s_{0}, s_{1}\right]$} & $(55.89,4.40,0.19)$ & 0.06 \\
$B_{210}$ & {$\left[s_{1}, s_{1}\right]$} & $(69.10,6,37,0.16)$ & 0.09 \\
$B_{211}$ & {$\left[s_{0}, s_{1}\right]$} & $(55.89,4.40,0.19)$ & 0.08 \\
$B_{212}$ & {$\left[s_{1}, s_{2}\right]$} & $(78.64,7.12,0.31)$ & 0.07 \\
$B_{213}$ & {$\left[s_{1}, s_{1}\right]$} & $(69.10,6,37,0.16)$ & 0.11 \\
$B_{31}$ & {$\left[s_{0}, s_{1}\right]$} & $(55.89,4.40,0.19)$ & 0.16 \\
$B_{32}$ & {$\left[s_{0}, s_{1}\right]$} & $(55.89,4.40,0.19)$ & 0.13 \\
$B_{33}$ & {$\left[s_{0}, s_{0}\right]$} & $(50.00,3.93,0.10)$ & 0.12 \\
$B_{34}$ & {$\left[s_{0}, s_{1}\right]$} & $(55.89,4.40,0.19)$ & 0.08 \\
$B_{35}$ & {$\left[s_{1}, s_{2}\right]$} & $(78.64,7.12,0.31)$ & 0.19 \\
$B_{36}$ & {$\left[s_{0}, s_{0}\right]$} & $(50.00,3.93,0.10)$ & 0.10 \\
$B_{37}$ & {$\left[s_{1}, s_{1}\right]$} & $(69.10,6,37,0.16)$ & 0.22 \\
\hline
\end{tabular}

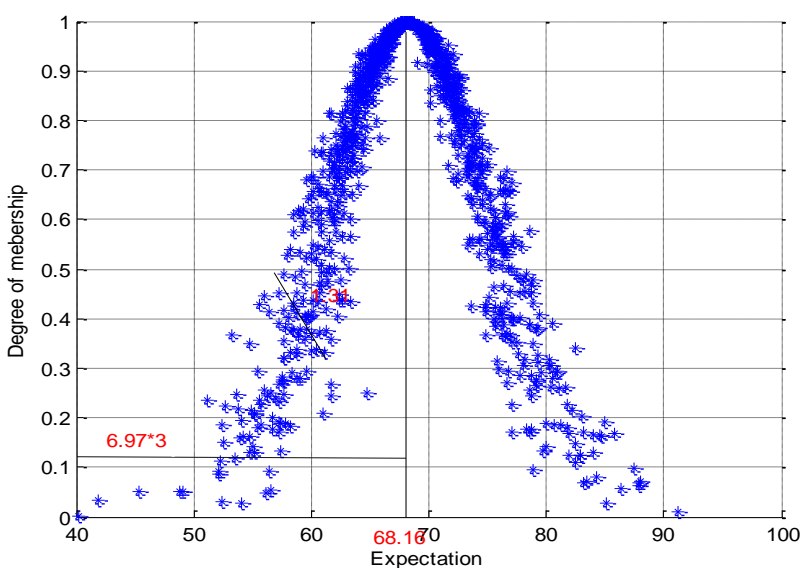

Figure 4. The evaluation result cloud.

In the result of the evaluation model, the entropy $E_{n}$ is 7.97 and ultra-entropy $H_{e}$ is 0.96 . As mentioned in the previous section, the entropy $E_{n}$ is a measure of concentration and stability about assessment model, and the ultra-entropy $H_{e}$ is a measure of fuzziness and randomness of natural linguistic information. From the results of the entropy $E_{n}$ and ultra-entropy $H_{e}$, we can see that concentration and stability of the assessment model can be accepted. From the final result, the energy utilization comprehensive evaluation of carbon performance in this project is 68.16, and the class of the river multi-purpose project is "Average".

As can be seen from the three indicators in the criterion level, score for design indicator is higher than the other two ones, which means the designers paid great attention to reducing carbon emissions in the engineering design stage, but did not do well in the course of implementation. As a result, 
scores in the operation indicator is lower than in the construction indicator. Therefore, in order to reduce carbon-dioxide emissions, we should not only pay attention to the design phase, but also the construction and operation phases. As for each indicator in different phases, which is influenced by different factors, the scores they received are certainly different. In the project design phase, the designers pay more attentions to environmental protection, and scores are relatively better than other phases. Especially, the scores of utilization rate of renewable energy and energy consumption are the highest. Due to the limitation of cost, there are some restrictions for the application of advanced technology, so scores of the efficiency of equipment, energy saving technology and renewable energy technology are lower. In the construction phase, most indicator scores show a trend of decline, largely because the technology used in the project cannot meet the requirement of energy conservation and reuse. However, since the location of project is near the Xiangjiang River, the sewage disposal ability is stronger; therefore, the score of water utilization rate is higher than others. In the operation phase, comprehensive evaluation value goes downward again, mainly because of the limitations of the project management and funding. Similarly, score of sewage pollution emissions is the highest one. Thus, technology used in public projects has a significant influence on the low carbon. Based on the evaluation results, we can take targeted measures to improve the carbon performance.

\section{Conclusions}

Environmental protection is the responsibility of each country over the long run, and the energy utilization assessment is the key measure of low-carbon of public projects. The purpose of this study is to establish an indicator system and a model to assess energy utilization of low-carbon in public projects. In this paper, we set up an energy utilization of carbon performance indicator system in public projects, which includes 27 indicators in three phases of the projects. Based on the indicator system, FAHP was applied to cumulate weight of indicators and cloud model was used to process linguistic information given by the experts, which cannot be assessed with explicit numerical values. Then, as an example, the multi-purpose Xingjiang River project has been studied in detail. It can be seen that the indicator system and the proposed model are feasible and effective. Through the analysis of the indicator scores, it is obvious that the key to reduce carbon emission is to make full use of advanced technology, which can reduce carbon emissions and damage to the environment to a large extent. Another important way is to increase the renewable energy utilization. The indicator system that we established can be used as an inspection reference for governments or project managers when monitoring and determining public projects, and the proposed model can be seen as an alternative way to evaluate energy utilization of carbon performance in public projects. This paper also supports the low carbon concept, which will promote sustainable development of society, environment and economy.

Acknowledgments: This paper is supported by the National Natural Science Foundation of China $(71473076,71573078)$.

Author Contributions: This paper is the result of the joint effort of all the authors. Ziran Tang collected the indicators information and the project data. Li Ma wrote the "Introduction" and calculated "Empirical Result". Lin Li and Fangfang Fan designed the methodology. Fangfang Fan wrote the section titled "Evaluation Model of Carbon Performance". Lin Li wrote the sections titled" Empirical Results" and "Conclusion". All authors read and approved the final manuscript.

Conflicts of Interest: The authors declare no conflict of interest.

\section{References}

1. Global Economic Data. Macro Economy, China. 2015. Available online: http://www.qqjjsj.com/zgjjdt/ 45160.html (accessed on 17 May 2015).

2. Lin, G.C. Urban China in transformation: Hybrid economy, juxtaposed space, and new testing ground for geographical enquiries. Chin. Geogr. Sci. 2011, 21, 1-16. [CrossRef]

3. Xu, X.N. Low Carbon GDP. Southern Metropolis Daily. 3 December 2010. Available online: http://gd.news. sina.com.cn/news/2010/12/03/1060930.html (accessed on 10 July 2015).

4. Cust, J. Using intermediate indicators: Lessons for climate policy. Clim. Policy 2009, 9, 450-463. [CrossRef] 
5. Lal, D. Methods of Project Analysis: A Review; The World Bank: Washington, DC, USA, 1974.

6. Green, R.H.; Doyle, J.R.; Cook, W.D. Preference voting and project ranking using DEA and cross-evaluation. Eur. J. Oper. Res. 1996, 90, 461-472. [CrossRef]

7. Rodney, H. Improving the performance of Earned Value Analysis as a construction project management tool. Eng. Constr. Arch. Manag. 2000, 7, 399-411.

8. Yeung, J.F.; Chan, A.P.; Chan, D.W.; Li, L.K. Development of a partnering performance index (PPI) for construction projects in Hong Kong: A Delphi study. Constr. Manag. Econ. 2007, 25, 1219-1237. [CrossRef]

9. Gabriel, A.; Rafael, A. Probabilistic control of project performance using control limit curves. J. Constr. Eng. Manag. 2007, 133, 957-965.

10. Lee, S.K.; Mogi, G.; Hui, K.S. A fuzzy analytic hierarchy process (AHP)/data envelopment analysis (DEA) hybrid model for efficiently allocating energy R\&D resources: In the case of energy technologies against high oil prices. Renew. Sustain. Energy Rev. 2013, 21, 347-355.

11. Seung, H.H.; Myung, J.C.; Keon, S.I. Six sigma-based approach to improve performance in construction operations. J. Manag. Eng. 2008, 24, 21-31.

12. Zhang, L.N.; Peng, X.J. Evaluation on Urban Low-Carbon Economy Development of Cities. Adv. Mater. Res. 2014, 850, 1339-1342. [CrossRef]

13. Hai, L.Y.; Yang, X.; Han, W.H. A Study on the Index System for Evaluating Low Carbon Economy of Resource-Based Region Based on AHP. Adv. Mater. Res. 2014, 869, 935-941. [CrossRef]

14. Jorgenson, A.K.; Clark, B. The relationship between national-level carbon dioxide emissions and population size: An assessment of regional and temporal variation, 1960-2005. PLoS ONE 2013, 8, 1960-2005. [CrossRef] [PubMed]

15. Koji, S.; Yoshitaka, T.; Kei, G.; Yuzuru, M. Developing a long-term local society design methodology towards a low-carbon economy: An application to Shiga Prefecture in Japan. Energy Policy 2007, 35, 4688-4703.

16. Zhang, J.; Zeng, W.; Wang, J.; Yang, F.; Jiang, H. Regional low-carbon economy efficiency in china: Analysis based on the super-sbm model with $\mathrm{CO}_{2}$ emissions. J. Clean. Prod. 2015, 111, 1-10. [CrossRef]

17. Nieto-Morote, A.; Ruz-Vila, F. A fuzzy approach to construction project risk assessment. Int. J. Proj. Manag. 2011, 29, 220-231. [CrossRef]

18. Guo, H. The Evaluation of Low-carbon Economic Development-Based on the Comprehensive Fuzzy Algorithm. Contemp. Econ. Manag. 2010, 32, 15-18.

19. Shaw, K.; Shankar, R.; Yadav, S. Global supplier selection considering sustainability and carbon footprint issue: AHP multi-objective fuzzy linear programming approach. Int. J. Oper. Res. 2013, 17, 215-247. [CrossRef]

20. Michael, A.B.P.; Carla, A.M.D.; Katrina, C.A.; Kathrine, G.T. Evaluating Climate Change Mitigation Options in the Philippines with Analytic Hierarchy Process (AHP). J. Chem. Eng. 2013, 13, 234-251.

21. Zadeh, L.A. The concept of a linguistic variable and its application to approximate reasoning-III. Inf. Sci. 1975, 9, 43-80. [CrossRef]

22. Cabrerizo, F.J.; Pérez, I.J.; Herrera-Viedma, E. Managing the consensus in group decision making in an unbalanced fuzzy linguistic context with incomplete information. Knowl. Based Syst. 2010, 23, 169-181. [CrossRef]

23. Fan, Z.P.; Liu, Y. A method for group decision-making based on multi-granularity uncertain linguistic information. Expert Syst. Appl. 2010, 37, 4000-4008. [CrossRef]

24. Zhu, J.J.; Wang, H.H.; Chen, Y.; Qin, L. Project evaluation method using non-formatted text information based on multi-granular linguistic labels. Inf. Fusion 2015, 24, 93-107. [CrossRef]

25. Delgado, M.; Verdegay, J.L.; Vila, M.A. Linguistic decision-making models. Int. J. Intell. Syst. 1992, 7, 479-492. [CrossRef]

26. Jiang, Y.P.; Fan, Z.P.; Ma, J. A method for group decision making with multi-granularity linguistic assessment information. Inf. Sci. 2008, 178, 1098-1109. [CrossRef]

27. Bordogna, G.; Fedrizzi, M.; Pasi, G. A linguistic modeling of consensus in group decision making based on OWA operators. IEEE Trans. Syst. Man Cybern. A 1997, 27, 126-133. [CrossRef]

28. $\mathrm{Xu}, \mathrm{Z}$.S. A method based on fuzzy linguistic assessments and linguistic ordered weighted averaging (OWA) operator for multi-attribute group decision making problems. Syst. Eng. 2002, 20, 79-82.

29. Tan, C.; Wu, D.D.; Ma, B. Group decision making with linguistic preference relations with application to supplier selection. Expert Syst. Appl. 2011, 38, 14382-14389. [CrossRef] 
30. Herrera, F.; Herrera-Veda, E.; Martinez, L. A fusion approach for managing multi-granularity linguistic term sets in decision making. Fuzzy Sets Syst. 2000, 114, 43-58. [CrossRef]

31. Yang, W.; Chen, Z. New aggregation operators based on the Choquet integral and 2-tuple linguistic information. Expert Syst. Appl. 2012, 39, 2662-2668. [CrossRef]

32. Wang, J.Q.; Wang, D.D.; Zhang, H.Y.; Chen, X.H. Multi-criteria group decision making method based on interval 2-tuple linguistic information and Choquet integral aggregation operators. Soft Comput. 2015, 19, 389-405. [CrossRef]

33. Li, D.; Cheung, D.; Shi, X. Uncertainty Reasoning Based on Cloud Models in Controllers. Comput. Math. Appl. 1998, 35, 99-123. [CrossRef]

34. Li, D.Y.; Du, Y. Uncertainty Artificial Intelligence; National Defense Industry Press: Beijing, China, 2005.

35. Wang, J.Q.; Wang, P.; Wang, J.; Zhang, H.Y.; Chen, X.H. Atanassov's Interval-Valued Intuitionistic Linguistic Multi-criteria Group Decision-Making Method Based on the Trapezium Cloud Model. Trans. Fuzzy Syst. 2015, 23, 542-554. [CrossRef]

36. Li, D.; Du, Y. Artificial Intelligence with Uncertainty; Chapman \& Hall/CRC Press: Boca Raton, FL, USA, 2007.

37. Li, D.; Liu, C.; Gan, W. A new cognitive model: Cloud model. Int. J. Intell. Syst. 2009, 24, 357-375. [CrossRef]

38. Feng, Y.Q.; Wang, H.L.; Cao, M.K. Intelligent decision support system based on cloud model. In Proceeding of the 2006 Chinese Control and Decision Conference, Tianjin, China, 27 July 2006; pp. 1081-1084.

39. Yan, C.S.; Li, Y.J. Analysis of dynamic consumer detailed segmentation model based on cloud model. J. Harbin Inst. Technol. 2007, 39, 299-302.

40. Zhang, J.; Zhang, J.A.; Sun, P. Trust evaluation model based on cloud model for C2C electronic commerce. Comput. Syst. Appl. 2010, 19, 83-87.

41. Qin, K.; Xu, K.; Liu, F.; Li, D. Image segmentation based on histogram analysis utilizing the cloud model. Comput. Math. Appl. 2011, 62, 2824-2833. [CrossRef]

42. Wang, J.Q.; Lu, P.; Zhang, H.Y.; Chen, X.H. Method of multi-criteria group decision-making based on cloud aggregation operators with linguistic information. Inf. Sci. 2014, 274, 177-191. [CrossRef]

43. Zhang, A.P.; Zhang, X.H. Method of multi-attribute decision making on linguistic interval information. Comput. Eng. Appl. 2011, 47, 156-158.

44. Zhang, Z.; Guo, C.H. A method for multi-granularity uncertain linguistic group decision making with incomplete weight information. Knowl. Based Syst. 2012, 26, 111-119. [CrossRef]

45. Bao, G.Y.; Lian, X.L.; He, M.; Wang, L.L. Improved two-tuple linguistic representation model based on new linguistic evaluation scale. Control Decis. 2010, 25, 780-784.

46. Fu, B.; Li, D.G.; Wang, M.K. Review and prospect on research of cloud model. Appl. Res. Comput. 2011, 28, $420-426$.

47. Jim, W.; Rob, B.; David, O.; Michele, S. Lessons from China: Building technological capabilities for low carbon technology transfer and development. Clim. Chang. 2015, 131, 387-399.

48. Qian, Y.; Cong, B.L. An optimization model of machining process route for low carbon manufacturing. Int. J. Adv. Manuf. Technol. 2015, 80, 1181-1196.

49. Kuo, T.C.; Chen, H.M.; Liu, C.Y. Applying multi-objective planning in low-carbon product design. Int. J. Precis. Eng. Manuf. 2014, 15, 241-249. [CrossRef]

50. Zhang, Z.Q.; Qu, J.S.; Zeng, J.J. A quantitative comparison and analysis on the assessment indicators of greenhouse gases emission. J. Geogr. Sci. 2008, 18, 387-399. [CrossRef]

51. Chomaitong, S.; Perera, R. Adoption of the low carbon society policy in locally-governed urban areas: Experience from Thai municipalities. Mitig. Adapt. Strateg. Glob. Chang. 2014, 19, 1255-1275. [CrossRef]

52. Saaty, T.L. Making and validating complex decisions with the AHP/ANP. J. Syst. Sci. Syst. Eng. 2005, 14, 1-36. [CrossRef]

53. Pipatprapa, A.; Huang, H.-H.; Huang, C.H. A Novel Environmental Performance Evaluation of Thailand's Food Industry Using Structural Equation Modeling and Fuzzy Analytic Hierarchy Techniques. Sustainability 2016, 8, 246. [CrossRef]

54. Calabrese, A.; Costa, R.; Menichini, T. Using Fuzzy AHP to manage Intellectual Capital assets: An application to the ICT service industry. Expert Syst. Appl. 2013, 40, 3747-3755. [CrossRef]

55. Shaw, K.; Shankar, R.; Yadav, S.S.; Thakur, L.S. Supplier selection using fuzzy AHP and fuzzy multi-objective linear programming for developing low carbon supply chain. Expert Syst. Appl. 2012, 39, 8182-8192. [CrossRef]

56. Lu, Y.J. Weight calculation method of fuzzy analytical hierarchy process. Fuzzy Syst. Math. 2002, 16, 79-85. 
57. Li, D.Y.; Meng, H.J.; Shi, X.M. Membership clouds and membership cloud generators. Comput. Res. Dev. 1995, 32, 15-20.

58. $\mathrm{Xu}, \mathrm{Z}$.S. A direct approach to group decision making with uncertain additive linguistic preference relations. Fuzzy Optim. Decis. Mak. 2006, 5, 21-32. [CrossRef]

59. Wang, H.L.; Feng, Y.Q. On multiple attribute group decision making with linguistic assessment information based on cloud model. Control Decis. 2005, 20, 679-685.

60. Wang, J.Q.; Peng, J.J.; Zhang, H.Y.; Liu, T.; Chen, X.H. An uncertain linguistic multi-criteria group decision-making method based on a cloud model. Group Decis. Negot. 2015, 24, 171-192. [CrossRef]

(C) 2016 by the authors; licensee MDPI, Basel, Switzerland. This article is an open access article distributed under the terms and conditions of the Creative Commons Attribution (CC-BY) license (http://creativecommons.org/licenses/by/4.0/). 